\title{
Solid Waste Management in Nairobi, Kenya. A case for emerging economies.
}

\author{
Muniafu, M. and Otiato, E.
}

\begin{abstract}
Industrialization and globalization have increased the quantity and quality of goods that are produced and moved around the world mainly through trade. This has led to an increased generation of waste since due to availability; items are discarded with no real attachment or need for repair. Improved quality has seen the use of materials, which are either synthetic or not common in high concentrations in natures living life cycles and thus are potentially hazardous when released from consumer products into the environment. The question of what to do with human trash has been of concern to every society and over time, the concerned local authorities have set up waste collection and disposal systems. There are numerous reasons why we need to be concerned with waste. It is costly to dispose of, and the generation of large amounts of wastes impacts the environment. Domestic and industrial discharges of waste contaminate air, land and water with pollutants and toxics that can harm human and animal health and plant life. Waste technologies must therefore grow hand in hand with changing societal complexities to cope with the high volumes and new types of wastes produced. The question of cost also arises and becomes significant where national economies are weak or disorganized.
\end{abstract}

The paper gives an overview of the solid waste technology status in the capital city of a slowly industrializing country in Africa, Kenya, and suggests a way forward in improving waste technology. Currently the city, Nairobi, lacks an effective waste management system leading to high possibilities of negative short and long-term impacts on human health and the environment in general. To overcome these, there are wide ranges of requirements and suggested solutions, which include creation and enforcement of waste management policies as well as procedures, incentives, community participation, education and awareness, proper waste collection procedures and disposal sites among others.

Key words: Solid waste management, open dumpsite, policies, legislature

\section{Introduction}

On a broad scale, the situation of waste in so-called developing countries cannot be considered in isolation since industrialization and globalization have increased the quantity and quality of goods that are produced and moved around the world mainly through trade. This, together with increasing human population, has led to an increased generation of waste as items (due to greater availability) are discarded with no real attachment or need for repair. 
Improved quality has seen the use of materials, which are either synthetic or not common in high concentrations in nature's life cycles and are thus potentially hazardous when released from consumer products into the environment. The end result is that some developing countries are left in a dilemma on how to handle the increasing waste given their weak economies (and thus low technical capacities and poor physical infrastructures), inabilities to enforce environmental legislation, financial mismanagement and poor administrative capacities. There exists a lot of literature on solid waste management (SWM) in the developing countries (Cointreau, 1982; ThomasHope, 1995; IIC, 1990) which analyze the current situations and reasons behind them as well as suggesting solutions.

Ogawa (1996) further points out that a number of SWM projects have been carried out in developing countries with many failing to support themselves or to expand further when external agencies discontinue their support. The author puts blame for this on both parties since on the one hand, recipient countries and cities accept whatever resources that are provided to them without considering their subsequent resource requirements. External support agencies, on the other hand, among other reasons, may not fully understand local conditions influencing the selection of appropriate SWM systems in addition to being restricted in amount of resources they can provide or in mandates and modes under which they can operate.

This paper looks at the waste situation of Nairobi, the capital city of Kenya. The country's population was projected as $36,900,000$ in mid-2007 by the Population Reference Bureau (2008). As is typical in most capitals of African countries, its population has continued to grow without proportionality to the relevant infrastructural services. Its current waste situation provides an opportunity for an academic discourse on possible implication and solutions with the various stakeholders. Indeed, the Sustainable Initiatives Development Centre (SUDIC) of the United States International University Africa (USIU-A) held a Waste Management Inception Conference on the $15^{\text {th }}$ to $17^{\text {th }}$ August, 2006 in Nairobi with participants drawn from industry, the local city council, institutes of higher learning and waste collecting companies among others. Some of findings and recommendations will be shown in the paper along with more recent developments in waste management initiatives in Nairobi.

\section{Population and Structure of the city}

The city's population was 2,087, 008 by the 1999 Census (GOK, 2001) with projections by JICA (1998) putting it close to 3,600,000 inhabitants by the year 2008. Nairobi contains almost $50 \%$ of all Kenya's urban population (GOK, 2001). The structure of the city is a legacy of both the colonial era and the later planning capabilities of its local authority. There are planned portions (dating from colonial times) with later modifications of more intense buildings especially flats in previously large single house compounds.

Waste collection is not an issue in such areas which occupy about $70 \%$ of the city as most of the residents are able and willing to pay the fees (ranging from 20 to 40 USD per 
month) charged by private collection companies. Population densities in this section range from 2 to 40 people per hectare (Mitulla, 2003). There are also unplanned and poorly planned portions of the city where settlements grew up haphazardly without access roads, drainage or prior improvement of the land. Such areas, although being only 30 to $40 \%$ of the city's total area, contain up to about $70 \%$ of the city's population with population densities of up to 1,250 people per hectare.

Basic services, such as adequate water supply, sanitation and housing, are poor. Garbage collection by the City Council is extremely poor, with many areas never being served or only once in several months. As a result, garbage is dumped in the open, and accumulates in huge mounds (Frijns et al 1997). Mungai (1995) points out that the waste has become a problem in Nairobi, due to increasing urbanization without adequate disposal sites and transportation. There have been efforts by non-governmental organizations working with communities to recycle waste such as paper, plastic and metals. The impact of this, however, remains minimal.

\section{Waste Generation and Composition}

According to Afdb (2002), a total of 1, 530 tonnes per day of solid wastes are generated in the City of Nairobi with an apparent specific gravity of 0.28 . Taking the 1999 census figures for the City of Nairobi to be 2,143,254 people, then the amount of solid wastes generated per day per person is approximately $0.714 \mathrm{~kg}$ per person per day.

If the collection efficiency of $25 \%$ is used, arithmetically $65 \%$ of the solid wastes generated is uncollected and this translates to 1,147.50 tonnes/day. This could be more due to increasing population in urban areas and several increasing industrial activities from many sectors including health facilities.

Table 1. Trends in wastes generation in the City of Nairobi

\begin{tabular}{|l|r|}
\hline Year & Amount Generated/Day \\
\hline 1973 & $452.66^{1}$ \\
\hline 1975 & $501.92^{1}$ \\
\hline 1985 & $850.86^{1}$ \\
\hline 1998 & $1,426.00^{2}$ \\
\hline 2002 & $1,530.00^{3}$ \\
\hline 2004 & $2,347.00^{4}$ \\
\hline 2015 & $2,679.89^{5}$ \\
\hline
\end{tabular}

Data from Afdb (2002)

Polythene bags and plastics, including PVC items, make up approximately 225 tonnes out of the 2000 tonnes of solid waste generated daily in Nairobi (KAM, 2003). This represents about $11 \%$ of total waste generated daily, while $75 \%$ comprises biodegradable waste that can be composted. The remaining percentage is made up of other recyclable materials such as textiles, metal and glass making up $2.7 \%, 2.6 \%$ and $2.3 \%$ respectively. 
Industries have developed with the advent of technology, resulting in a myriad of wastes being generated from the industrial processes. Industrial wastes can be classified into two categories; these are hazardous and non-hazardous wastes. The include used cleaning solvents, unusable hazardous materials, defective materials, raw material packaging, unusable paints and adhesives, used blast media, effluent and sludge, used oil, spent leadacid vehicle batteries and used dry batteries among others.

\section{Collection and Disposal of Waste}

It has been the responsibility of local authorities through Local Government Act Cap 265 to manage solid waste. However, for close to two decades services provided by the local authorities have been on the decline thus other players have come on board, In Nairobi, the City Council recruitment of private collectors who are estimated to be 60 in number in 1998 are able to collect about $25 \%$ of the generated wastes (JICA, 1998). Examples of the large companies include Bins Nairobi Services Limited (does not collect toxic or hazardous waste), Domestic Refuse Disposal Services (DRDS), Citibins, Waa Ship Garbage Collector, Mukuru Garbage Collectors, Nairobi Airport Services (NAS) and Kenya Refuse Handlers Limited among others.

An operational weakness has been that there was no system in place for registering them and they were only issued with a business permit. Recently, however, a mechanism has begun to take shape and waste collection companies have to demonstrate capacity and meet certain standards to get a permit. Some of the private companies complain about a lack of a clear policy on the part of the local city authority (NCC) especially on how it wants to develop the future of waste collection and disposal and it thus relies on short term decisions that are only designed to solve problems in the present situation. There is also no real policing of standards within waste collectors.

The end disposal of Nairobi's waste is open dumping at a site located at Dandora, in the Eastland's section of the city (although there is a minimal amount of disposal by open burning and incineration, the ash also ends up in Dandora open dumpsite). It is $7.5 \mathrm{~km}$ southeast of the centre of Nairobi. The dumpsite covers an area of 26.6 hectares. As shown in the map, although this site was several kilometres away from the city centre, the rapid growth of population has resulted in settlements encroaching upon the dumpsite. This together with the fact that it is inappropriate waste disposal method (by 1998, it was filled with approximately 1.3 million cubic meters and is inadequate to continue handling all the waste that is generated daily by the city, which is estimated at over 1,200 tonnes) saw the projection of an alternative site in Ruai, Nairobi. However, due to inaction, this area is now settled and any talk of relocating the dumpsite there results in controversy.

\section{Impacts of the Dandora Open Dumpsite}

Areas adjacent to the site, that is, Dandora, Korogocho and Kariobangi estates experience several problems caused by the various activities carried out at the dumpsite. These problems need to be addressed as a matter of urgency to save the deteriorating situation. These estates together form a network of residential housing units for over 250,000people. The increased demand for low income housing in Nairobi over the last 
three decades has meant that the dumpsite is now almost at the heart of these estates. The following problems were identified during the field trip to Dandora dumpsite by a delegation of delegates to the Waste Management Inception conference:

\section{Poor infrastructure}

Despite the large amounts of wastes brought at the Dandora dumpsite, the roads are no where to be seen. This is because the wastes have spilled to the roads that were initially there and also lack of discipline by those bringing the wastes to the dumpsite. These people dispose of the waste on the roads instead of taking them inside the dump other than on the ways. Eventually, the roads have disappeared but wastes continue to be brought in this dumpsite.

There is also poor drainage systems which has seen most of the waste end up in rivers that pass near the dumpsite. The water in these rivers is used by the residents which causes a high potential risk to human health. A good example is the Nairobi River which is highly polluted by wastes from the dumpsite.

\section{Uncontrolled and indiscriminate dumping}

Years of uncontrolled and indiscriminate dumping at the site has given rise to huge mountains of industrial, medical and domestic wastes, for which no action has been taken other than incessant and reckless burning that leaves a perpetual cloud of noxious fumes permanently hovering the adjacent neighbourhoods. Due to the composition of these types of waste which is a mixture of toxic and non-toxic, there is always spontaneous combustion which also contributes to the forming clouds that prevent fresh air from reaching these areas adjacent to the site.

\section{Pollution}

As one approaches the dumpsite; you can hardly escape the horrendous stench from the composting wastes at the site. There is high pollution of air, soil and water all around the dumpsite and the adjacent areas. Air pollution is due to the spontaneous combustions that occur among the wastes as well as the open burning usually carried out by those who visit the dumpsite either to collect food and other items which are later on sold to the residents who live around the dumpsite or done by the local authorities. Garden farming around the site is poor due to the soil pollution. The soil around the site is highly polluted and therefore not conducive for any type of crop. The garbage mounds attract flies, rats and scavenger birds (such as marabou storks) which are a nuisance to the residents who live adjacent to the site.

The rivers flowing in and around the dumpsite are contaminated with leachates that continue to percolate into the rivers and even the water table. These waters are commonly used by neighbouring communities to water their plants and animals as well as for domestic use such as washing clothes and bathing.

\section{Health risks}

The unrestricted access means that each day, scores of families brave the noxious fumes to scavenge raw materials, much of which eventually finds its way back to 
neighbourhoods as animal feed and even human food. Stray chicken, pigs, goats, dogs and cats roam the dumpsite eating the toxic matter and becoming vectors of pests and parasites that are eventually transferred to the surrounding home and hence causing diseases to both animals and human beings. For example, free-range chicken eggs collected near the Dandora dumpsite outside Nairobi showed high levels of dioxins (and PCBs) which exceeded background levels by almost 18-fold and were more than six times higher than the European Union (EU) dioxin limit for eggs (ENVILEAD, 2005). Lack of proper apparel for the resource people at the site also contributes to contracting diseases as they are exposed to very poor sanitation. The health risks are evidenced by the ever increasing number of clinics and chemists around the site and the adjacent estates.

\section{Security risks}

The dumpsite is used as a hide out for thugs, carjackers, muggers and many others of this kind. Weapons are allegedly hidden within the dumpsite to be used for performing different mischievous activities. Security of the residents around the site is calling. The unrestricted access to the dumpsite means that anybody can access the dumpsite whenever he/she wants anytime. Many unfortunate passersby have been killed or injures in and around the dumpsite.

\section{Lack of employment}

The dumpsite has created a perceived dependency on some of the neighbouring communities who consider themselves entirely dependant on it for their livelihoods. Poverty and unemployment among the residents are the main contributing factors to this kind of lifestyle. The resource recovery people, as they are commonly referred to, collect different materials in the dumpsite after which they earn about 1 USD per day. This money is never enough for the families. There is great need to train these people on money management, banking, social development and their rights.

\section{Policies and Legislature on waste}

All legislature and policies on solid waste management have been the preserve of the local councils through the Local Government Act Cap 265. The responsibilities of the local authorities have included the provision of legal/regulatory frameworks, of institutional arrangements, of financial strategies and of technical systems.

The establishment of the National Environment Management Authority (NEMA) has seen it having bigger mandate in enforcing and ensuring compliance with broader environmental laws. The Environmental Management Coordination Act (EMCA) of 1999, for example, established a legal framework for the management of pesticides, toxic and hazardous chemicals. Section 92 of the Act empowers the Minister for Environment and Natural Resources to make regulations prescribing the management of toxic and hazardous chemicals including classification, registration, importation, exportation, packaging and advertising among others.

NEMA is thus the principal government agency in all matters relating to environmental management with its mission being to safeguard and enhance the quality of the environment through coordination, research, facilitation and enforcement, while 
encouraging responsible individual, corporate and collective participation towards sustainable development.

Here, enforcement is regarded as the use of legal tools to assist in and compel compliance with environmental requirements, to establish liability or responsibility for harm to the public or to the environment caused by practices that pollute. It provides an element of fairness for those who comply with requirements through the possible imposition of economic disadvantageous upon those who choose to violate the law. It also provides an economic incentive for those complying.

Compliance, on the other hand, is a state in which environmental requirements are met and conformity with those requirements is maintained. Thus, an effective industrial compliance and enforcement programme is an integral part of the environmental quality management cycle.

Some of the measures taken so far by NEMA include, creating an overall framework to create a fair playing ground for all players, capacity building and training, to ensure that it has the capacity to enforce compliance and effective management. A lot of work still remains to be done

Major shortcomings identified in waste management legislature include the inability to force waste generators to reduce the amount and toxicity of waste, ensuring that people pay for waste disposal and instilling order in the waste transportation system, which is at best, chaotic. There are also significant legal loopholes and no system to make people responsible for waste generation and to be liable for their actions, that is, everyone in the waste management chain. Further to these, environmental assessment audits are not carried out at disposal sites and hazardous wastes are still disposed of in the dumpsite. Lastly, the waste collection companies need to be inspected to ensure that they have met various safety standards with criteria established for entrepreneurs wishing to register these companies.

\section{Recommendations and the Way Forward}

1. Putting in place an ideal waste management system that embraces a technical approach including collection and transportation plans, waste reduction, recycling and disposal plans. It should have improved management and regulatory systems that embrace an institutional and financial approach including legal, private sector and public education and awareness plans.

2. There should be greater public involvement through intolerance to waste mismanagement. This will exert pressure on the authorities and WM agencies who will otherwise remain relaxed.

3. Costing of waste management systems to allow for their incorporation into budgets is now a must. Many local authorities do not have it as an annual expenditure. 
4. Waste collection efficiency by both private and public operators should be improved.

5. Development of waste management policys that will address all types of wastes ranging from medical to industrial. This calls for a speeding up of the process of developing and finalizing regulations, guidelines and standards on solid waste management as set out by the environmental legislature.

6. Establish appropriate economic policies to encourage the development of the comprehensive technologies for utilizing solid waste e.g. Brick-making and cement making.

7. Establishment of waste transfer stations where intense settlements do not allow for landfills that are close. These reduce overall community truck traffic, offer flexibility in waste handling and disposal options, reduce air pollution, fuel consumption and road wear, allow for screening of waste, reduce traffic at the disposal facility and offer citizens facilities for convenient drop-off of waste and recyclables.

8. Involve corporate companies through their corporate social responsibility (CSR) plans. Many companies already know that for the long-term survival of businesses, they must nurture their markets and that creating social and environmental values is as important for their long-term survival as generating economic capital.

9. Put in place certain monitoring processes and empower NEMA and the relevant institutions, improve access to information and auditing processes, systems and records to be developed. Penalties and incentives should also be put in place.

\section{References}

Afdb. 2002. Study on Solid Wastes Management Options for Africa. Project Report. www.afdb.org/pls/portal/url/ ITEM/F5F4CC9E2105E31EE030A8C0668C631A ambient and non-ambient matter for epidemiology and risk assessment: Why and how. Journal of Air and Wastes Management Association, 50:1167-1183.

Cointreau, S. 1982. Environmental Management of Urban Solid waste in Developing Countries: A Project Guide. Urban Development Technical Paper Number 5, World Bank, Washington DC.

ENVILEAD, 2005. Contamination of chicken eggs near the Dandora dumpsite in Kenya by dioxins, PCBs and hexachlorobenzene "Keep the Promise, Eliminate POPs!" Campaign Report. Prepared by Dioxin, PCBs and Waste WG of the International POPs Elimination Network (IPEN) Secretariat, ENVILEAD (Kenya) and Arnika Association (Czech Republic) Nairobi - Prague (March-16-2005)

Frijns, J., Kirai, P., Malombe, J., and Vlviet BV. (1997). Pollution Control of Small-Scale Metal Industries in Nairobi.GSC Van Gils BV, Wageningen

Government of Kenya (2001) 1999 Population and Housing Census Volume I Central Bureau of Statistics Nairobi 
IIC (Institute for International Cooperation) 1990. Japan International Cooperation Agency. "Improvement of Solid Waste Management in Developing Countries." December 1990

JICA. 1998). The Study on Solid Wastes Management in Nairobi City in the Republic of Kenya. JICA Final report, Nairobi City Council, August.

Mungai, G. 1998. Solid Waste Management and its Environmental Impact in Kenya. In: Solid Waste management: Critical issues for developing countries (Ed. Elizabeth Thomas-Hope, 159 - 167. Kingston: Canoe Press, 1998.

Ogawa, H. 1996. Sustainable Solid Waste Management in Developing Countries Paper was presented at the 7th ISWA International Congress and Exhibition, Parallel Session 7, "International Perspective". Yokohama. Japan. October/November 1996.

Thomas-Hope, E. ed. 1998. Solid Waste management: Critical issues for developing countries. Kingston: Canoe Press.

Winnie Mitullah, 2005. UNDERSTANDING SLUMS: Case Studies for the Global Report on Human Settlements 2003 http://www.ucl.ac.uk/dpuprojects/Global_Report/pdfs/Nairobi.pdf 